\title{
Friction Performance Optimization of Chemically Deposited Ni-P-W Coating Using Taguchi Method
}

\author{
Supriyo Roy and Prasanta Sahoo \\ Department of Mechanical Engineering, Jadavpur University, Kolkata 700032, India \\ Correspondence should be addressed to Prasanta Sahoo; psjume@gmail.com
}

Received 17 April 2012; Accepted 17 June 2012

Academic Editors: B. A. Akash, G. Nikas, and H. Zhu

Copyright (C) 2013 S. Roy and P. Sahoo. This is an open access article distributed under the Creative Commons Attribution License, which permits unrestricted use, distribution, and reproduction in any medium, provided the original work is properly cited.

\begin{abstract}
The present study considers the friction behavior of chemically deposited Ni-P-W coatings and optimization of the coating process parameters for minimum friction using Taguchi method. The study is carried out by varying the combination of four coating process parameters, namely, concentration of nickel source, concentration of reducing agent, concentration of tungsten source, and annealing temperature. The friction tests are conducted in a plate-on-roller configuration by keeping the coated sample fixed against a rotating steel roller. The optimum combination of process parameters for minimum friction coefficient is obtained from the analysis of $\mathrm{S} / \mathrm{N}$ ratio. Furthermore, a statistical analysis of variance reveals that the concentration of nickel source solution has the most significant influence in controlling friction characteristics of Ni-P-W coating. The surface morphology and composition of coatings are also studied with the help of scanning electron microscopy, energy dispersed x-ray analysis, and x-ray diffraction analysis.
\end{abstract}

\section{Introduction}

Coating process is the most efficient technique to improve the performance capabilities of metal surfaces, by allowing the mechanical properties of the substrate material to be maintained while protecting them against wear, friction, or corrosion by a protective coating. The electroless plating/chemical deposition was first adopted by Brenner and Riddell $[1,2]$. It is a method of plating metallic substrates with nickel or cobalt alloys without the application of any external current source. In general, this type of plating is characterized by the selective reduction of metal ions only at the surface of a catalytic substrate immersed into an aqueous solution of metal ions, with continued deposition on the substrate through the catalytic action of the deposit itself. Since the deposit catalyzes the reduction reaction, the term autocatalytic is also used to describe the plating process. In this process the substrate develops a potential when it is dipped in electroless solution called bath that contains a source of metallic ions, reducing agent, complexing agent, stabilizer, and other components [3]. Due to the developed potential both positive and negative ions are attracted towards the substrate surface and release their energy through charge transfer process, and this property gives it an extra advantage over the conventional electroplating processes that depend on an external source of direct current in order to reduce nickel ions in the electrolyte to nickel metal on the substrate. Another advantage is that these coatings can be applied to a variety of substrate materials and plated uniformly on intricate part geometries. The deposition rate, properties of coated components, and the structural behaviour of deposits mainly depend upon the plating bath constituents and conditions such as the type and concentrations of the reducing agent, stabilizer, used $\mathrm{pH}$, and the temperature of the bath. Since the discovery of these coatings, the properties and structures of such coatings have received considerable research attention. Hypophosphite reduced nickel phosphorous and borohydride reduced nickel-boron coating have already gained immense popularity due to excellent hardness, anticorrosion, and tribological properties [4]. The amount of phosphorous deposited in the coating and postdeposition heat treatment determines 
the properties and microstructures of the coatings. The basic nickel-phosphorus deposits with high amount of phosphorous show good wear resistance, particularly when heattreated at $400-600^{\circ} \mathrm{C}$ [5-9]. The structure of as-plated EN coatings has been reported to be either crystalline or amorphous or a mixture of both. The mechanical and tribological properties of these coatings can be further improved by the incorporation of hard particles and dry lubricants [10$15]$.

In the field of tribology, there are two major categories of nickel-based composite coatings, that is, lubricating composite coatings and wear-resistant composite coatings. The electroless Ni-P based lubricating composite coatings usually contain codeposited solid lubricants such as $\mathrm{WS}_{2}, \mathrm{MoS}_{2}$, PTFE (poly tetra fluoroethylene), and graphite [16], and they usually have a reduced friction coefficient as compared with binary electroless Ni-P coating. It is considered that the incorporation of a typically transition metal such as $\mathrm{W}, \mathrm{Co}, \mathrm{Mn}, \mathrm{Re}$, and Mo in the binary Ni-P alloy could lead to superior properties than the binary Ni-P coating. So the research could be extended for the ternary Ni-P-M alloy where the $\mathrm{M}$ is the transition metal. Addition of a third element into the binary electroless nickel to form a ternary alloy coating such as $\mathrm{Ni}-\mathrm{Cu}-\mathrm{P}$ [17], $\mathrm{Ni}-\mathrm{P}-\mathrm{TiO}_{2}$ [18], Ni-W-P [19-23] has been studied.

Very few data are available on the friction properties of electroless ternary or quaternary systems. Pearlstein and Weightman [24] first presented the ternary Ni-W-P alloy in 1963 , and since then, many investigations on electroless Ni$\mathrm{P}-\mathrm{W}$ ternary alloy are reported. As tungsten is a refractory metal, it cannot be deposited from any aqueous solution. However tungsten alloys with the iron group transition metals can be readily deposited from aqueous solutions containing tungsten ion [21]. The incorporation of tungsten into the nickel matrix led to the solute hardening and enhanced the hardness and also exhibits excellent properties such as mechanical properties, tribological properties, and corrosion resistance. The friction coefficient was found to be within the range $0.35-0.65$ when tested under the $40 \mathrm{~N}$ loading conditions [25].

This study deals with the application of the Taguchi method to determine the optimum combination of coating process parameters in order to obtain minimum friction behaviour in electroless Ni-P-W coatings. Ni-P-W coatings are deposited on mild steel (AISI 1040) specimens based on the Taguchi orthogonal design with four design parameters (each has three levels), namely, concentration of nickel source, concentration of reducing agent, concentration of tungsten source, and annealing temperature as independent variables. Then the friction behaviour of these coatings is evaluated in a multitribotester. The Taguchi analysis is employed to identify optimum coating parameter combination that yields optimum (minimum) friction coefficient. A confirmation experiment is conducted to verify the optimal coating process parameter combination as predicted by Taguchi analysis. The analysis of variance is also performed to determine the significance level of individual factors and their interactions. The surface morphology and composition of the coatings are studied with the help of scanning electron microscopy (SEM), energy dispersed $\mathrm{x}$-ray analysis, and $\mathrm{x}$-ray diffraction (XRD) analysis.

\section{Taguchi Method}

An attempt has been made in this paper to optimize the friction behaviour of chemically deposited Ni-P-W coating using Taguchi method [26]. The concept of the Taguchi method is to optimize process parameters to achieve high quality with low cost. Taguchi recommends the use of the loss function to measure the quality characteristic. The value of the loss function is further transformed into a statistical measure called signal-to-noise ratio. A larger $\mathrm{S} / \mathrm{N}$ ratio represents a better quality characteristic, and the corresponding process parameters are insensitive to the variation of environmental conditions and other noise factors. Due to the increasing number of process parameters, a special design of orthogonal arrays is used in the Taguchi method to reduce large number of experiments that need to be carried out. The detailed methodology about Taguchi method is described elsewhere [27].

\section{Experimental Details}

3.1. Plan of Investigation. The design of experiment is a wellorganized method where the values of the design factors can be changed to study the effects of the individual factors as well as their interaction on the responses with a least number of experimental runs. The design process parameters are those factors which are varied within a specific range to obtain an optimum combination for desired result of the responses. In the present study, four coating process parameters are selected; those are concentration of nickel source (A), concentration of reducing agent (B), concentration of tungsten source (C), and the annealing temperature (D). Each factor has three equally spaced levels. The factors and their levels considered in the present study are shown in Table 1. As it is a four-factor three-level experiment, so the total degree of freedom (DOF) considering the individual factors and their interactions is 20 . Here $\mathrm{L}_{27}$ orthogonal array is chosen as it satisfies all the DOF conditions. The orthogonal array is shown in Table 2.

3.2. Preparation of Substrate. Mild steel blocks (AISI 1040) of size $20 \mathrm{~mm} \times 20 \mathrm{~mm} \times 8 \mathrm{~mm}$ are used as substrates for the deposition of electroless Ni-P-W coating. This particular dimension of the substrate is chosen so that the samples get well fitting with the counterpart of the multitribotester apparatus for tribological testing. Shaping, parting, and milling processes are used accordingly for the preparation of the sample. The sample is then subjected to surface grinding process.

As the friction property of any surface is dependent on the roughness of the surface, so for convenience it is required that all of the uncoated specimens should have same surface roughness. But practically it is almost impossible to have the same surface roughness for all of the specimens. 
TABLE 1: Design factors and their levels.

\begin{tabular}{|c|c|c|c|c|}
\hline \multirow{2}{*}{ Design factors } & \multirow{2}{*}{ Unit } & \multicolumn{3}{|c|}{ Levels } \\
\hline & & 1 & 2 & 3 \\
\hline Concentration of source of nickel (nickel sulfate solution) (A) & $\mathrm{g} / \mathrm{L}$ & 20 & $25^{\mathrm{a}}$ & 30 \\
\hline Concentration of reducing agent (sodium hypophosphite solution) (B) & $\mathrm{g} / \mathrm{L}$ & 14 & $17^{\mathrm{a}}$ & 20 \\
\hline Concentration of source of tungsten (sodium tungstate) (C) & $\mathrm{g} / \mathrm{L}$ & 15 & $20^{\mathrm{a}}$ & 25 \\
\hline Annealing temperature (D) & ${ }^{\circ} \mathrm{C}$ & 400 & $500^{\mathrm{a}}$ & 600 \\
\hline
\end{tabular}

${ }^{\mathrm{a}}$ Initial condition.

TABLE 2: $\mathrm{L}_{27}$ Orthogonal array with design factors and interactions.

\begin{tabular}{|c|c|c|c|c|c|c|c|c|c|c|c|c|c|}
\hline Trial no. & $1(\mathrm{~A})$ & $2(\mathrm{~B})$ & $3(\mathrm{~A} \times \mathrm{B})$ & $4(\mathrm{~A} \times \mathrm{B})$ & $5(\mathrm{C})$ & $6(\mathrm{~A} \times \mathrm{C})$ & $7(\mathrm{~A} \times \mathrm{C})$ & $8(B \times C)$ & $9(\mathrm{D})$ & 10 & $11(\mathrm{~B} \times \mathrm{C})$ & 12 & 13 \\
\hline 1 & 1 & 1 & 1 & 1 & 1 & 1 & 1 & 1 & 1 & 1 & 1 & 1 & 1 \\
\hline 2 & 1 & 1 & 1 & 1 & 2 & 2 & 2 & 2 & 2 & 2 & 2 & 2 & 2 \\
\hline 3 & 1 & 1 & 1 & 1 & 3 & 3 & 3 & 3 & 3 & 3 & 3 & 3 & 3 \\
\hline 4 & 1 & 2 & 2 & 2 & 1 & 1 & 1 & 2 & 2 & 2 & 3 & 3 & 3 \\
\hline 5 & 1 & 2 & 2 & 2 & 2 & 2 & 2 & 3 & 3 & 3 & 1 & 1 & 1 \\
\hline 6 & 1 & 2 & 2 & 2 & 3 & 3 & 3 & 1 & 1 & 1 & 2 & 2 & 2 \\
\hline 7 & 1 & 3 & 3 & 3 & 1 & 1 & 1 & 3 & 3 & 3 & 2 & 2 & 2 \\
\hline 8 & 1 & 3 & 3 & 3 & 2 & 2 & 2 & 1 & 1 & 1 & 3 & 3 & 3 \\
\hline 9 & 1 & 3 & 3 & 3 & 3 & 3 & 3 & 2 & 2 & 2 & 1 & 1 & 1 \\
\hline 10 & 2 & 1 & 2 & 3 & 1 & 2 & 3 & 1 & 2 & 3 & 1 & 2 & 3 \\
\hline 11 & 2 & 1 & 2 & 3 & 2 & 3 & 1 & 2 & 3 & 1 & 2 & 3 & 1 \\
\hline 12 & 2 & 1 & 2 & 3 & 3 & 1 & 2 & 3 & 1 & 2 & 3 & 1 & 2 \\
\hline 13 & 2 & 2 & 3 & 1 & 1 & 2 & 3 & 2 & 3 & 1 & 3 & 1 & 2 \\
\hline 14 & 2 & 2 & 3 & 1 & 2 & 3 & 1 & 3 & 1 & 2 & 1 & 2 & 3 \\
\hline 15 & 2 & 2 & 3 & 1 & 3 & 1 & 2 & 1 & 2 & 3 & 2 & 3 & 1 \\
\hline 16 & 2 & 3 & 1 & 2 & 1 & 2 & 3 & 3 & 1 & 2 & 2 & 3 & 1 \\
\hline 17 & 2 & 3 & 1 & 2 & 2 & 3 & 1 & 1 & 2 & 3 & 3 & 1 & 2 \\
\hline 18 & 2 & 3 & 1 & 2 & 3 & 1 & 2 & 2 & 3 & 1 & 1 & 2 & 3 \\
\hline 19 & 3 & 1 & 3 & 2 & 1 & 3 & 2 & 1 & 3 & 2 & 1 & 3 & 2 \\
\hline 20 & 3 & 1 & 3 & 2 & 2 & 1 & 3 & 2 & 1 & 3 & 2 & 1 & 3 \\
\hline 21 & 3 & 1 & 3 & 2 & 3 & 2 & 1 & 3 & 2 & 1 & 3 & 2 & 1 \\
\hline 22 & 3 & 2 & 1 & 3 & 1 & 3 & 2 & 2 & 1 & 3 & 3 & 2 & 1 \\
\hline 23 & 3 & 2 & 1 & 3 & 2 & 1 & 3 & 3 & 2 & 1 & 1 & 3 & 2 \\
\hline 24 & 3 & 2 & 1 & 3 & 3 & 2 & 1 & 1 & 3 & 2 & 2 & 1 & 3 \\
\hline 25 & 3 & 3 & 2 & 1 & 1 & 3 & 2 & 3 & 2 & 1 & 2 & 1 & 3 \\
\hline 26 & 3 & 3 & 2 & 1 & 2 & 1 & 3 & 1 & 3 & 2 & 3 & 2 & 1 \\
\hline 27 & 3 & 3 & 2 & 1 & 3 & 2 & 1 & 2 & 1 & 3 & 1 & 3 & 2 \\
\hline
\end{tabular}

Hence, all the substrates before coating are subjected to roughness evaluations (center line average values, $\mathrm{Ra}$ ), and the substrates which showed as little as about $0.1 \%$ variation in roughness are selected. The roughness measurements are carried out using a surface profilometer (Taylor Hobson, Surtronic 3+).

3.3. Coating Deposition. The substrate samples are mechanically cleaned from foreign matters and corrosion products. After that the samples are cleaned using distilled water. A pickling treatment is given to the specimens with dilute (50\%) hydrochloric acid for one minute to remove any surface layer formed like rust followed by rinsing in distilled water and methanol cleaning. A large number of trial experiments are performed before deciding the bath composition.

Table 3 indicates the bath composition and the operating conditions for successful coating of electroless Ni-P-W. Nickel sulphate is used as the source of nickel while sodium hypophosphite is the reducing agent. The bath is prepared by adding the constituents in appropriate sequence. The $\mathrm{pH}$ of the solution is maintained around 7-8 by continuous monitoring with a $\mathrm{pH}$ meter. The cleaned samples are activated in palladium chloride solution at a temperature of $55^{\circ} \mathrm{C}$. Activated samples are then submerged into the electroless bath which is maintained at a temperature between 90 and $92^{\circ} \mathrm{C}$ with the help of a hot plate cum stirrer attached with 
TABLE 3: Electroless bath composition and operating condition.

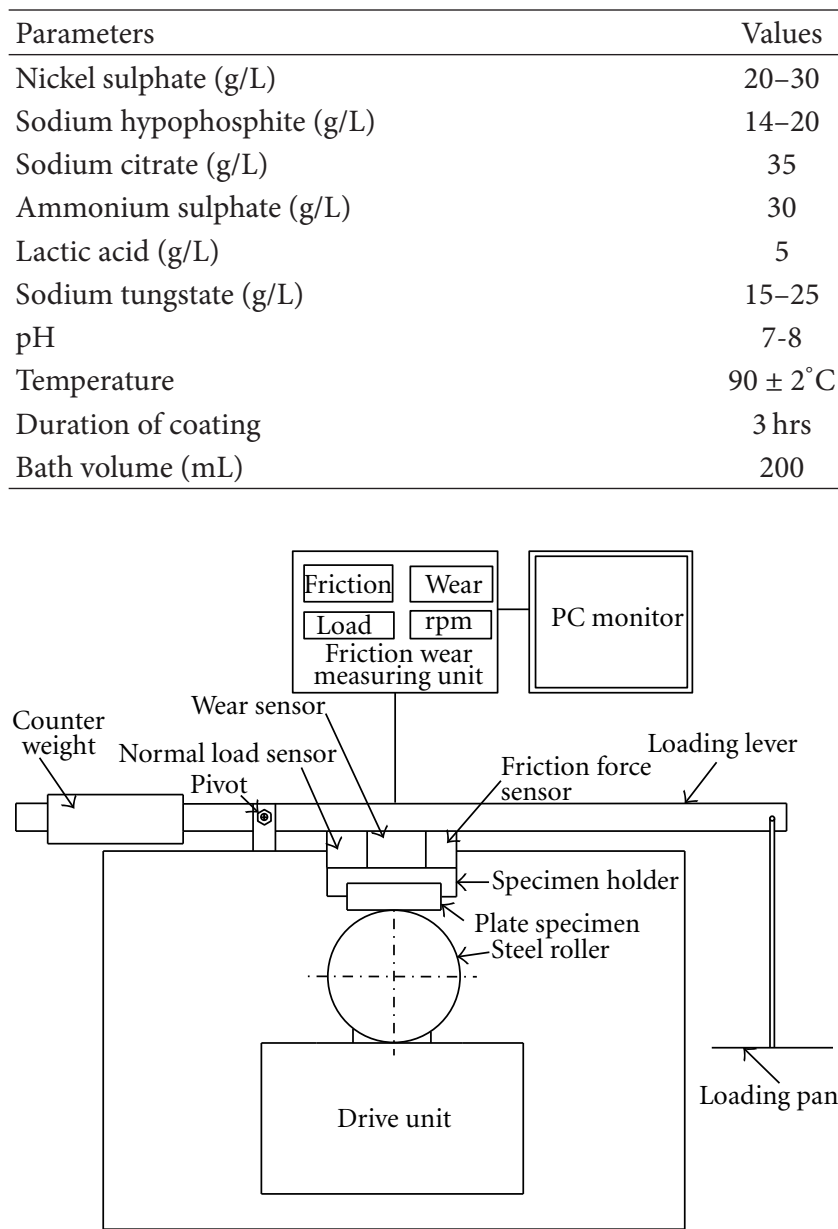

FIGURE 1: Schematic diagram of experimental setup.

a temperature sensor also submerged in the solution. The deposition is carried out for a period of 3 hours. The range of coating thickness is found to lie around 20-25 microns. After deposition, the samples are taken out of the bath and cleaned using distilled water. After coating, the samples are subjected to annealing at different temperatures $\left(400^{\circ} \mathrm{C}, 500^{\circ} \mathrm{C}\right.$, and $600^{\circ} \mathrm{C}$ ) as per the OA in Table 2.

3.4. Friction Test. Friction characteristics of the Ni-P-W coated specimens are studied under dry, nonlubricated conditions and at ambient temperature of about $25^{\circ} \mathrm{C}$ and relative humidity of about $85 \%$ in a multitribotester apparatus (TR25, Ducom, India) using a plate-on-roller configuration. A pictorial view of the apparatus is shown in Figure 1. The Ni$\mathrm{P}-\mathrm{W}$ coated specimens serve as test specimens which are held horizontally against a rotating roller of $50 \mathrm{~mm}$ dia $\times 20 \mathrm{~mm}$ thickness. The steel roller is coated with titanium nitride of hardness $85 \mathrm{HRc}$, which is higher than the hardness of the $\mathrm{Ni}-\mathrm{P}-\mathrm{W}$ coated specimen in order to ensure that the wear will take place only in the test specimens. Dead weights are placed on the loading pan, which is attached at one end of a $1: 5$ ratio loading lever. The frictional force is measured by a frictional
TABLE 4: Experimental results.

\begin{tabular}{lcc}
\hline SL. no. & COF & S/N ratio \\
\hline 1 & 0.465 & 6.6509 \\
2 & 0.553 & 5.1455 \\
3 & 0.562 & 5.0053 \\
4 & 0.558 & 5.0673 \\
5 & 0.515 & 5.7639 \\
6 & 0.452 & 6.8972 \\
7 & 0.551 & 5.1770 \\
8 & 0.527 & 5.5638 \\
9 & 0.635 & 3.9445 \\
10 & 0.753 & 2.4641 \\
11 & 0.549 & 5.2086 \\
12 & 0.518 & 5.7134 \\
13 & 0.468 & 6.5951 \\
14 & 0.543 & 5.3040 \\
15 & 0.652 & 3.7150 \\
16 & 0.559 & 5.0518 \\
17 & 0.438 & 7.1705 \\
18 & 0.456 & 6.8207 \\
19 & 0.552 & 5.1612 \\
20 & 0.559 & 5.0518 \\
21 & 0.437 & 7.1904 \\
22 & 0.485 & 6.2852 \\
23 & 0.801 & 1.9273 \\
24 & 0.82 & 1.7237 \\
25 & 0.532 & 5.4818 \\
26 & 0.851 & 1.4014 \\
27 & 0.722 & 2.8293 \\
\hline
\end{tabular}

force sensor that uses a beam type load cell of $1000 \mathrm{~N}$ capacity. The speed of the roller and the duration of tests can be controlled via a computer attached to the tribotester. The values of the tribological test parameters (normal load-25 $\mathrm{N}$, roller speed $-50 \mathrm{rpm}$, and sliding time $-300 \mathrm{sec}$ ) for the friction tests are kept constant for all the 27 specimens. Table 4 shows the experimental data obtained from the friction test.

3.5. Surface Morphology and Composition Study. The characterization of the coating is necessary so that it can be made sure that the coating is properly developed. An Xray diffraction (XRD) analyzer (Rigaku, Miniflex) is used for identification of compounds in the coatings both before and after heat treatment. Figure 2 shows the XRD plots of asdeposited and heat-treated conditions. From the figure it is evident that in as-deposited condition the phase is mostly amorphous but there exists a crystalline peak. Thus it may be attributed that the coated surface has a mixture of amorphous and crystalline phase. After heat treatment, some of the peaks broaden and produce crystalline phases. After heating at $500^{\circ} \mathrm{C}$ for 1 hour, the major peaks of $\mathrm{Ni}-\mathrm{W}$ and $\mathrm{Ni}_{3} \mathrm{P}$ are obtained.

Energy dispersive X-ray analysis (EDAX Corporation) is performed to determine the composition of the coating 


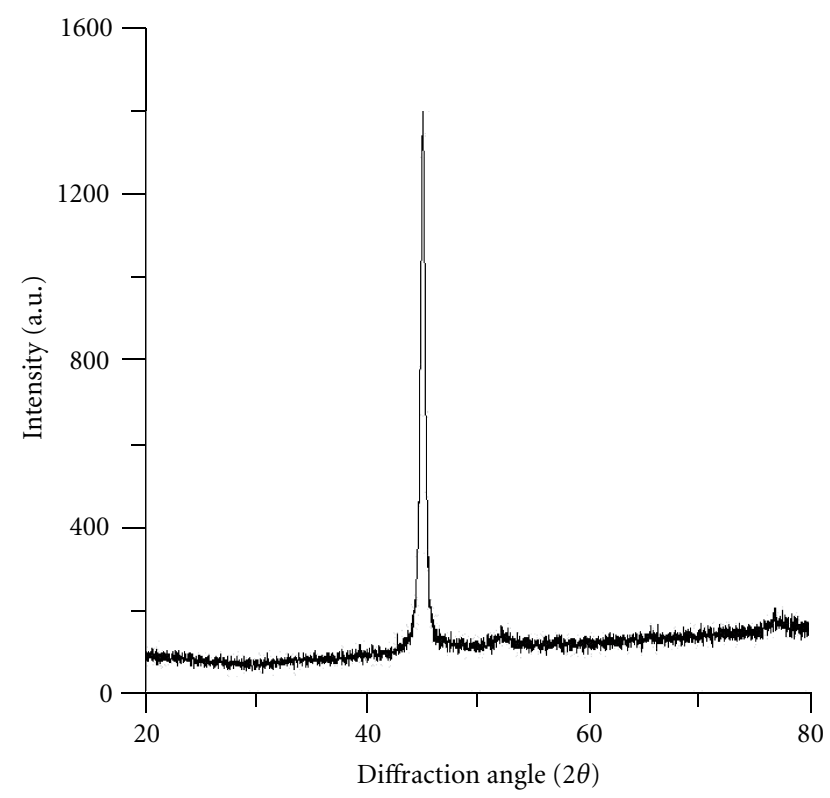

(a)

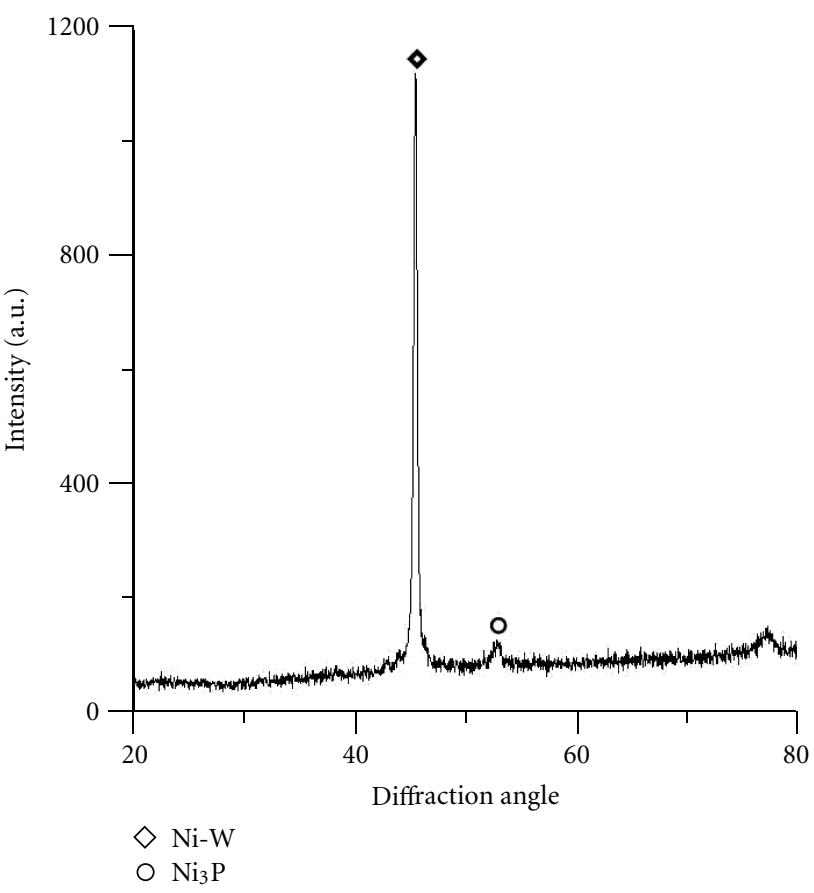

(b)

FIGURE 2: XRD plots of (a) as deposited condition, 2 (b) heat treated at $500^{\circ} \mathrm{C}$.

in terms of the weight percentages of nickel, phosphorous, and tungsten. The EDX analysis is done on the coatings developed from the bath consisting of different concentrations of sodium tungstate (tungsten ions) in order to capture the range of tungsten content in the coatings. Figure 3 shows the EDX spectra of the coated surface. Figure 4 shows the SEM micrograph of as-deposited and heat-treated $\left(400^{\circ} \mathrm{C}\right.$, $500^{\circ} \mathrm{C}$, and $\left.600^{\circ} \mathrm{C}\right) \mathrm{Ni}-\mathrm{P}-\mathrm{W}$ coated surface. It is clear that the deposit has globular shape with almost no porosity in

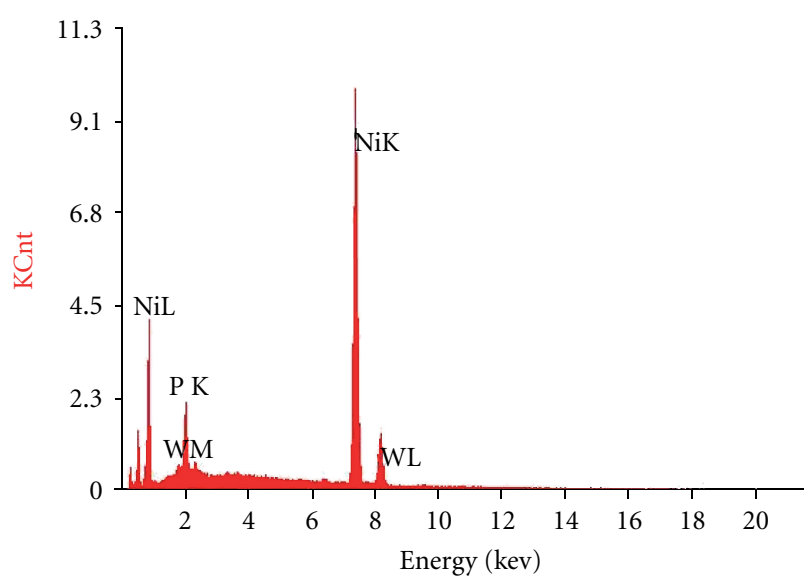

FIGURE 3: EDX spectra of coated surface.

as-deposited condition. When it is heat treated at $500^{\circ} \mathrm{C}$, the globules become more compact and produce a dense structure resulting in a hard deposit. With further heating at $600^{\circ} \mathrm{C}$, the globules increase in size and transform into coarse-grained structure. Figure 5 shows the SEM image of worn surface at different magnification. From the image it is clear that the load is taken by some of the peak globules where the other peaks remain intact. The wear mechanism is generally adhesive in nature because no plowing effect or abrasive particle is observed on the worn surface. The adhesive wear is influenced by several factors such as hardness and degree of adhesion between the interacting surfaces.

\section{Results and Discussion}

4.1. Analysis of Signal-to-Noise Ratio. Taguchi method is used to optimize process parameters to achieve high quality with low cost. Taguchi recommends the use of the loss function to measure the quality characteristic. The value of the loss function is further transformed into a statistical measure called signal-to-noise ratio; where signal means desirable value (mean) and the noise is the undesirable value (S.D.). A larger $\mathrm{S} / \mathrm{N}$ ratio represents a better quality characteristic because of the minimization of noise, and the corresponding process parameters are insensitive to the variation of environmental conditions and other noise factors. The variability can be easily captured if $\mathrm{S} / \mathrm{N}$ ratio is used to convert the experimental results into a value for the evaluation characteristic in the optimum parameter analysis, instead of the mean. The idea is to maximize the $\mathrm{S} / \mathrm{N}$ ratio, thereby minimizing the effect of random noise factors, which have a significant impact on the process performance. As the friction coefficient is to be minimized, so lower-the-better (LB) criterion of $\mathrm{S} / \mathrm{N}$ ratio is used which is given by

lower the better $(\mathrm{LB}): \frac{S}{N}$ ratio $=-10 \log \left(\frac{1}{n} \sum_{i=1}^{n} y_{i}^{2}\right)$, 


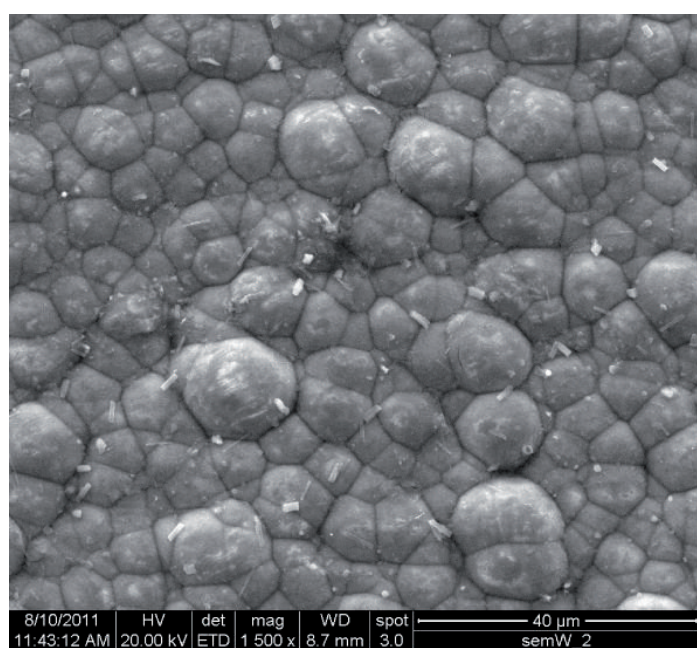

(a)

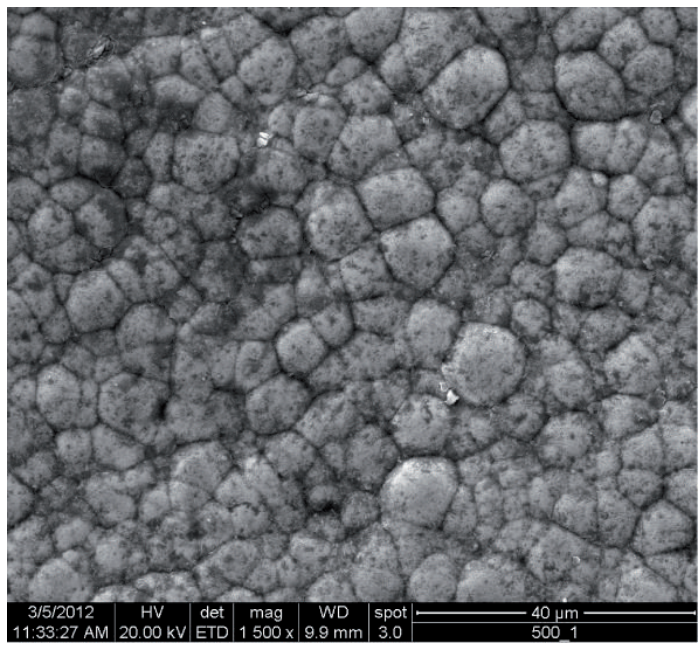

(c)

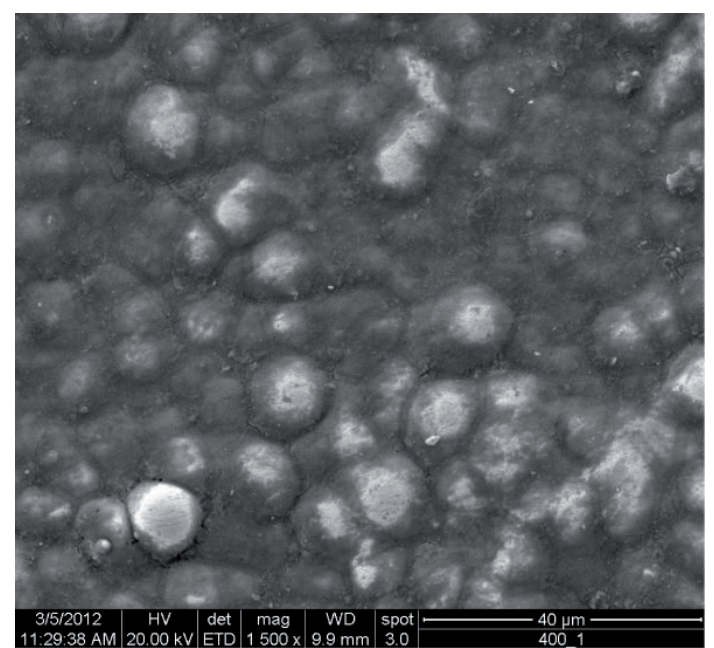

(b)

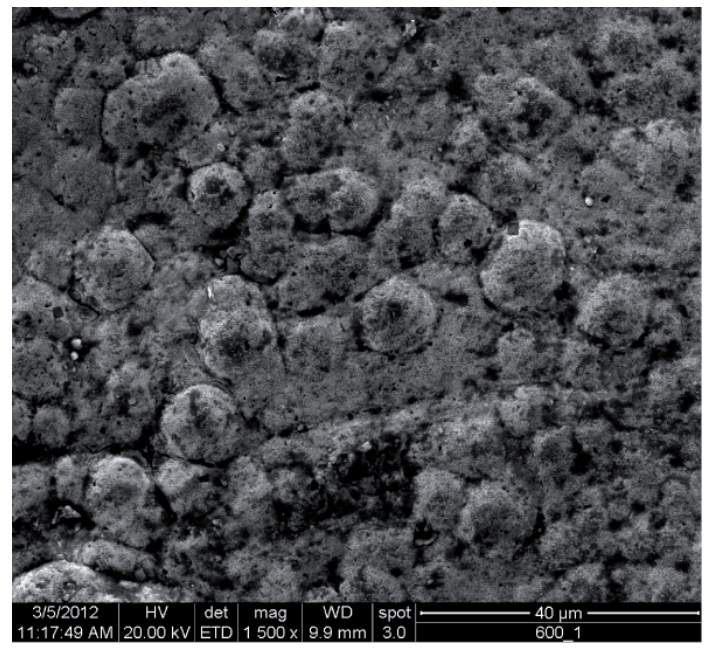

(d)

Figure 4: SEM image (a) as deposited, (b) annealed at $400^{\circ} \mathrm{C}$, (c) annealed at $500^{\circ} \mathrm{C}$, (d) annealed at $600^{\circ} \mathrm{C}$.

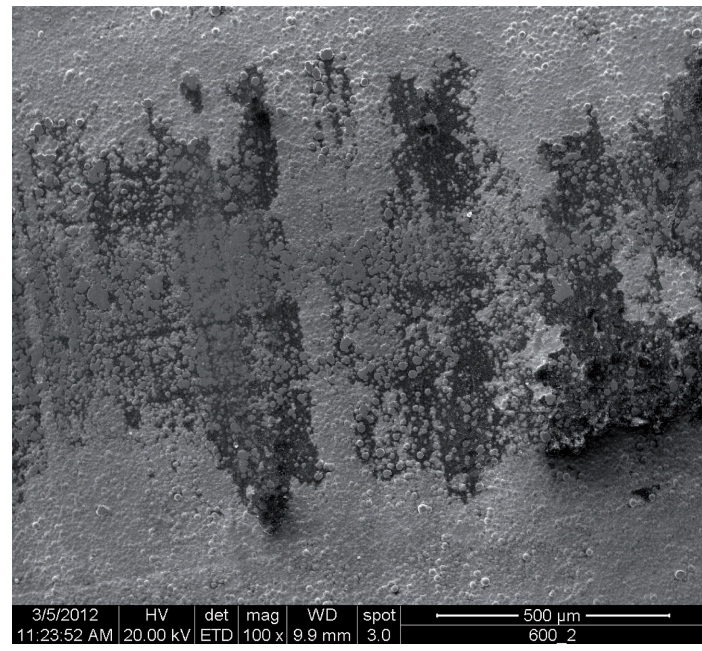

FIGURE 5: SEM image of worn surface. where $y$ is the observed data and $n$ is the number of observations. Table 4 shows the experimental results for friction coefficient and the corresponding $\mathrm{S} / \mathrm{N}$ ratio. Since the experimental design is orthogonal, it is then possible to separate out the effect of each coating parameter at different levels. The mean $\mathrm{S} / \mathrm{N}$ ratio for each level of the factors $\mathrm{A}-\mathrm{D}$ is summarized and called the $\mathrm{S} / \mathrm{N}$ response table for friction coefficient (Table 5). In addition, the total mean $\mathrm{S} / \mathrm{N}$ ratio for the 27 experiments is also calculated and listed in Table 5. All the calculations are performed using Minitab [28]. The response table shows the average of the selected characteristic for each level of the factors. The response table includes ranks based on Delta statistics, which compare the relative magnitude of effects. The Delta statistic is the highest average for each factor minus the lowest average for the same. Ranks are assigned based on Delta values; rank 1 is assigned to the highest Delta value, rank 2 to the second highest Delta value, and so on. The corresponding main effects and interaction effects plots between the process parameters are also shown 
TABLE 5: Response table for $\mathrm{S} / \mathrm{N}$ ratio.

\begin{tabular}{lcccc}
\hline Level & $\mathrm{A}$ & $\mathrm{B}$ & $\mathrm{C}$ & $\mathrm{D}$ \\
\hline 1 & 5.468 & 5.288 & 5.326 & 5.483 \\
2 & 5.338 & 4.809 & 4.726 & 4.678 \\
3 & 4.117 & 4.827 & 4.871 & 4.762 \\
Delta & 1.351 & 0.479 & 0.600 & 0.805 \\
Rank & 1 & 4 & 3 & 2 \\
\hline
\end{tabular}

Total mean $\mathrm{S} / \mathrm{N}$ ratio $=4.974417$

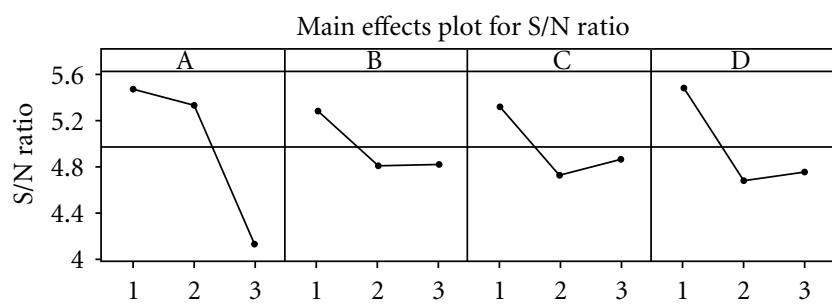

Figure 6: Main effect plot for coefficient of friction.

in Figures 6 and 7, respectively. In the main effects plot, if the line for particular parameter is near horizontal, the parameter has no significant effect. On the other hand, a parameter for which the line has the highest inclination will have the most significant effect. It is very clear from the main effects plot that parameter A (concentration of nickel source solution) is the most significant parameter while parameter D (annealing temperature) also has some significant effect. So far as the interaction plots are concerned, estimating an interaction means determining the nonparallelism of parameter effects. Thus, if the lines on the interaction plots are nonparallel, interaction occurs and if the lines cross, strong interactions occur between parameters. From Figure 7, it can be seen that there is strong interaction between parameters $\mathrm{A}$ and $\mathrm{B}$ and there is moderate interaction between $\mathrm{B}$ and $\mathrm{C}$ and parameters A and B. Thus from the present analysis it is clear that the concentration of nickel source solution (A) is the most influencing parameter for friction characteristics of EN coatings. The optimal process parameter combination is the one that yields maximum mean $\mathrm{S} / \mathrm{N}$ ratio, and thus the same for minimum friction coefficient is found to be A1B1C1D1.

4.2. Analysis of Variance (ANOVA). ANOVA is a statistical technique which can provide some important conclusions based on analysis of the experimental data. This method is very useful for revealing the level of significance of the influence of factor(s) or interaction of factors on a particular response. It separates the total variability of the response into contributions of each of the factors and the error. Using Minitab [28] ANOVA is performed to determine which parameter and interaction significantly affect the performance characteristics. Table 6 shows the ANOVA result for friction coefficient of EN coatings. ANOVA calculates the F-ratio, which is the ratio between the regression mean square and the mean square error. The F-ratio, also called the variance ratio, is the ratio of variance due to the effect
TABLE 6: Results of ANOVA.

\begin{tabular}{lccccc}
\hline Source & DF & SS & MS & $F$ & \% contribution \\
\hline A & 2 & 10.005 & 5.002 & $1.81^{*}$ & 13.8 \\
B & 2 & 1.328 & 0.664 & 0.24 & 1.8 \\
C & 2 & 1.763 & 0.881 & 0.32 & 2.5 \\
D & 2 & 3.523 & 1.761 & 0.64 & 4.9 \\
A * B & 4 & 18.481 & 4.62 & 1.67 & 25.6 \\
A * C & 4 & 12.938 & 3.235 & 1.17 & 17.9 \\
B * C & 4 & 7.619 & 1.905 & 0.69 & 10.5 \\
Error & 6 & 16.57 & 2.762 & & 23 \\
Total & 26 & 72.227 & & & \\
\hline
\end{tabular}

${ }^{*}$ Significant at $75 \%$ confidence level $F_{0.25,2,6}=1.76$.

of a factor and variance due to the error term. This ratio is used to measure the significance of the parameters under investigation with respect to the variance of all the terms included in the error term at the desired significance level, $\alpha$. If the calculated value of the F-ratio is higher than the tabulated value of the F-ratio, then the factor is significant at a desired $\alpha$ level. In general, when the $\mathrm{F}$ value increases, the significance of the parameter also increases. The ANOVA table shows the percentage contribution of each parameter. It is seen that parameter $\mathrm{A}$, that is, concentration of nickel source solution, has the most significant influence on friction coefficient at the confidence level of $75 \%$ within the specific test range. Similarly, the interaction of parameters $\mathrm{A} \times \mathrm{B}$ and $\mathrm{A} \times \mathrm{C}$ has some influence on friction property of the coating while interaction $\mathrm{B} \times \mathrm{C}$ has almost no contribution. This type of analysis is not available in the literature and will be useful for EN coating deposition with an objective of optimum friction behaviour within the particular range of process parameters.

4.3. Confirmation Test. Once the optimal level of process parameters has been found out, the next step is to predict and verify the improvement of the performance characteristic using the optimal level of the process parameters. The estimated grey relational grade, $\hat{\eta}$, using the optimal level of the process parameters can be calculated as

$$
\widehat{\eta}=\eta_{m}+\sum_{i=1}^{\mathrm{o}}\left(\bar{\eta}_{i}-\eta_{m}\right),
$$

where $\eta_{m}$ is the total mean $\mathrm{S} / \mathrm{N}$ ratio, $\bar{\eta}_{i}$ is the mean $\mathrm{S} / \mathrm{N}$ ratio at the optimal process parameter level, and o is the number of the main design process parameters that significantly affect the friction characteristics of electroless Ni-P-W coating. Table 7 shows the comparison of the estimated S/N ratio with the actual S/N ratio using the optimal parameters. The improvement of $\mathrm{S} / \mathrm{N}$ ratio from initial to optimal condition is $1.9494 \mathrm{~dB}$, which is about $39 \%$ of the mean $\mathrm{S} / \mathrm{N}$ ratio and is a significant improvement.

\section{Conclusion}

In the present study Taguchi orthogonal array is used to optimize the coating process parameters (concentration of 

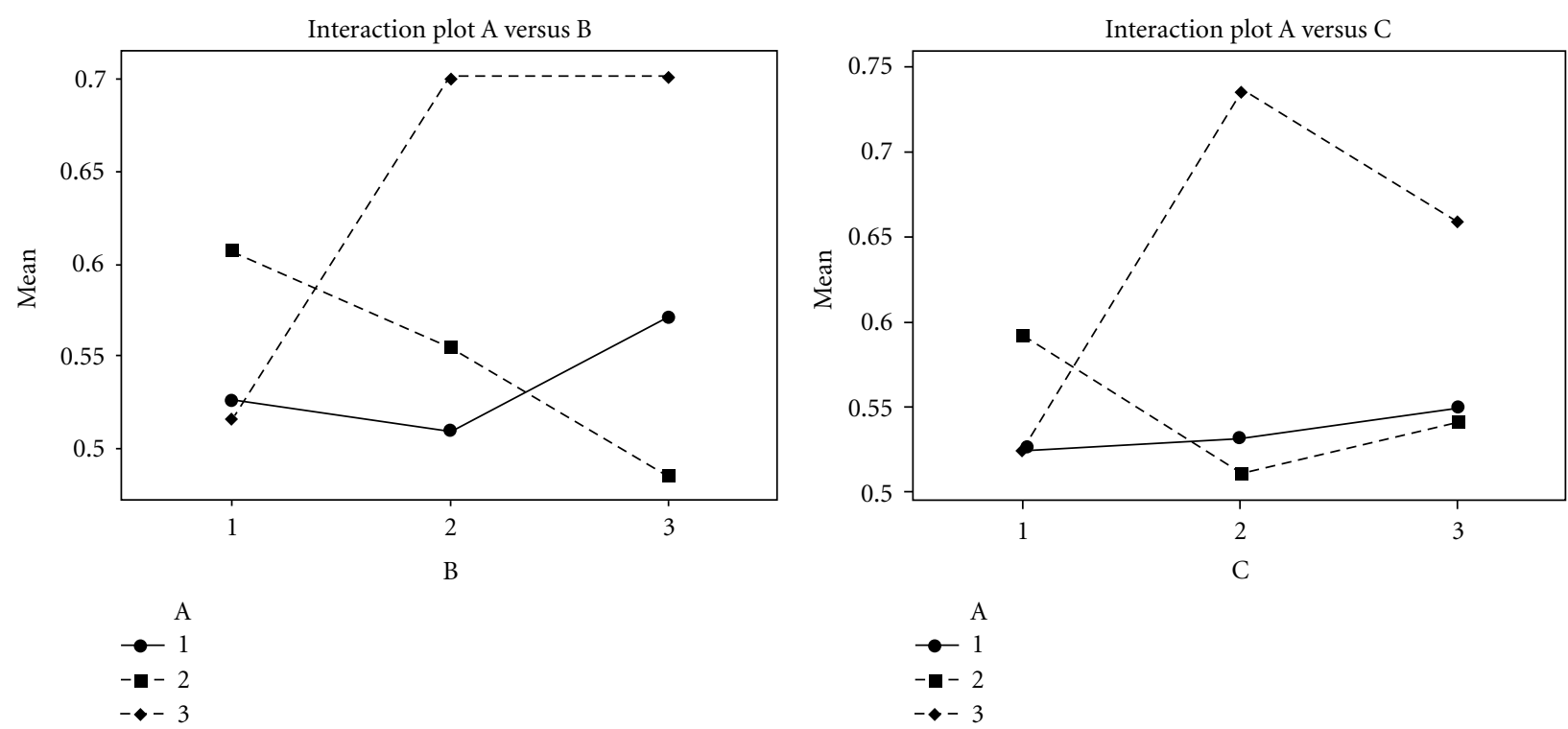

(a)

(b)
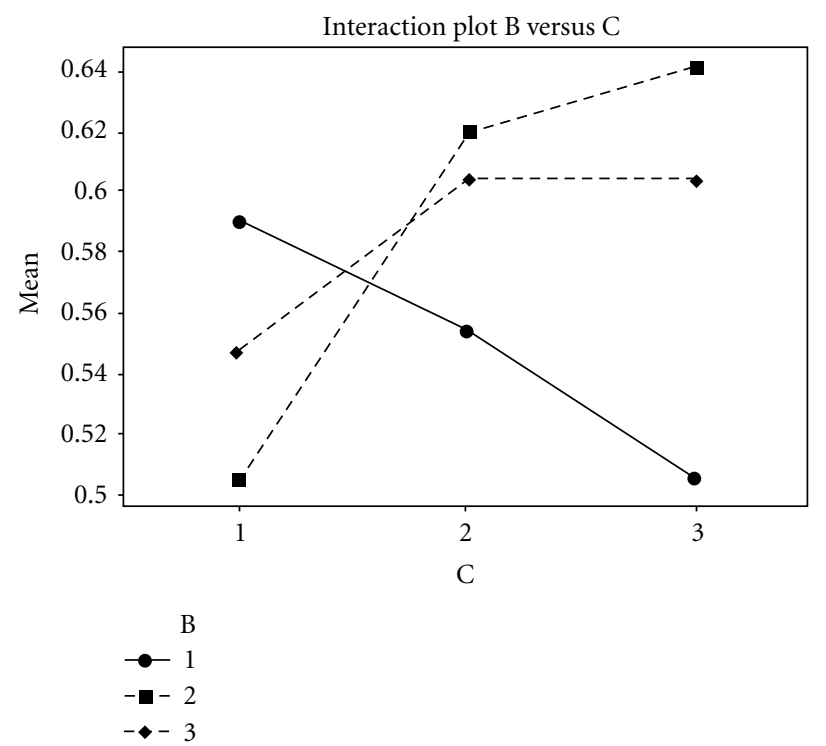

(c)

FIGURE 7: Interaction plots for friction coefficient, (a) between A\&B, (b) between A\&C, (c) between B\&C.

TABLE 7: Results of confirmation test.

\begin{tabular}{lccc}
\hline & Initial parameter level & \multicolumn{2}{c}{ Optimal parameter combination } \\
Prediction & Experimentation \\
\hline Level & A2B2C2D2 & & A1B1C1D1 \\
COF & 0.582 & & 0.465 \\
S/N ratio & 4.7015 & 5.4680 & 6.6509 \\
\hline \multicolumn{2}{l}{ Improvement of S/N ratio $=1.9494 \mathrm{~dB}$}
\end{tabular}

nickel source, concentration of reducing agent, concentration of tungsten source, and annealing temperature) together in order to minimize friction performance of $\mathrm{Ni}-\mathrm{P}-\mathrm{W}$ coating.
The optimal combination of coating parameters is obtained as A1B1C1D1. ANOVA result indicates that concentration of nickel source (A) is the most important parameter that significantly affects the friction characteristics at a confidence level of $75 \%$. The improvement of the $\mathrm{S} / \mathrm{N}$ ratio from the initial condition to the optimal condition is found to be about 39\%. From the EDX analysis it is clear that the coating is pure ternary and consists of nickel, phosphorous, and tungsten. The XRD plots reveal that the coating is a mixture of amorphous and crystalline structure in the as-deposited condition and turns crystalline after heat treatment. The Ni$\mathrm{P}-\mathrm{W}$ coating produces $\mathrm{Ni}-\mathrm{W}$ and $\mathrm{Ni}_{3} \mathrm{P}$ as major compounds when heat treated at $500^{\circ} \mathrm{C}$. From the surface morphology 
captured by SEM it is seen that there are many globular particles on the surface of the substrate with no surface damage. Also the coating is dense and with low porosity.

\section{References}

[1] A. Brenner and G. E. Riddell, "Nickel coating on steel by chemical reduction," Journal of Research of the National Bureau of Standards, vol. 37, no. 1, pp. 31-34, 1946.

[2] A. Brenner and G. E. Riddell, "Nickel plating on steel by chemical reduction," Proceedings of the American Electroplater's Society, vol. 33, p. 16, 1946.

[3] G. O. Mallory and J. B. Hadju, Electroless Plating: Fundamentals and Applications, AESF, Orlando, Fla, USA, 1991.

[4] P. Sahoo and S. K. Das, "Tribology of electroless nickel coatings - A review," Materials and Design, vol. 32, no. 4, pp. 1760-1775, 2011.

[5] R. Parkinson, "Properties and applications of electroless nickel deposits," Technical Series No. 10081, Nickel Development Institute, 1997.

[6] R. C. Agarwala and V. Agarwala, "Electroless alloy/composite coatings: A review," Sadhana - Academy Proceedings in Engineering Sciences, vol. 28, no. 3-4, pp. 475-493, 2003.

[7] O. Berkh, S. Eskin, and J. Zahavi, "Properties of electrodeposited NiP-SiC composite coatings," Metal Finishing, vol. 94, no. 3, pp. 35-40, 1996.

[8] D. Barker, "Electroless deposition of metals," Transactions of the Institute of Metal Finishing, vol. 71, no. 3, pp. 121-124, 1993.

[9] D. Baudrand and J. Bengston, "Electroless plating processes. Developing technologies for electroless nickel, palladium, and gold," Metal Finishing, vol. 93, no. 9, pp. 55-57, 1995.

[10] E. Vafaei-Makhsoos, E. L. Thomas, and L. E. Toth, "Electron microscopy of crystalline and amorphous Ni-P electrodeposited films: In-situ crystallization of an amorphous solid," Metallurgical Transactions A, vol. 9, no. 10, pp. 1449-1460, 1978.

[11] Y. Mori and S. Ohtsuka, Japanese Patent 50, 039, 638, 1975.

[12] I. Apachitei, J. Duszczyk, L. Katgerman, and P. J. B. Overkamp, "Electroless Ni-P composite coatings: The effect of heat treatment on the microhardness of substrate and coating," Scripta Materialia, vol. 38, no. 9, pp. 1347-1353, 1998.

[13] Y. S. Huang, X. T. Zeng, I. Annergren, and F. M. Liu, "Development of electroless NiP-PTFE-SiC composite coating," Surface and Coatings Technology, vol. 167, no. 2-3, pp. 207-211, 2003.

[14] G. Straffelini, D. Colombo, and A. Molinari, "Surface durability of electroless Ni-P composite deposits," Wear, vol. 236, no. 1-2, pp. 179-188, 1999.

[15] Q. Zhao, Y. Liu, H. Müller-Steinhagen, and G. Liu, "Graded NiP-PTFE coatings and their potential applications," Surface and Coatings Technology, vol. 155, no. 2-3, pp. 279-284, 2002.

[16] Y. Wu, H. Liu, B. Shen, L. Liu, and W. Hu, "The friction and wear of electroless Ni-P matrix with PTFE and/or SiC particles composite," Tribology International, vol. 39, no. 6, pp. 553-559, 2006.

[17] A. Abdel Aal and M. Shehata Aly, "Electroless Ni-Cu-P plating onto open cell stainless steel foam," Applied Surface Science, vol. 255, no. 13-14, pp. 6652-6655, 2009.

[18] W. Chen, W. Gao, and Y. He, "A novel electroless plating of Ni-P-TiO2 nano-composite coatings," Surface and Coatings Technology, vol. 204, no. 15, pp. 2493-2498, 2010.
[19] Y. J. Hu, T. X. Wang, J. L. Meng, and Q. Y. Rao, "Structure and phase transformation behaviour of electroless Ni-W-P on aluminium alloy," Surface and Coatings Technology, vol. 201, no. 3-4, pp. 988-992, 2006.

[20] F. B. Wu, S. K. Tien, J. G. Duh, and J. H. Wang, "Surface characteristics of electroless and sputtered Ni- P-W alloy coatings," Surface and Coatings Technology, vol. 166, no. 1, pp. 60-66, 2003.

[21] J. N. Balaraju and K. S. Rajam, "Electroless deposition of Ni$\mathrm{Cu}-\mathrm{P}, \mathrm{Ni}-\mathrm{W}-\mathrm{P}$ and Ni-W-Cu-P alloys," Surface and Coatings Technology, vol. 195, no. 2-3, pp. 154-161, 2005.

[22] S. K. Tien, J. G. Duh, and Y. I. Chen, "Structure, thermal stability and mechanical properties of electroless Ni-P-W alloy coatings during cycle test," Surface and Coatings Technology, vol. 177178, pp. 532-536, 2004.

[23] J. N. Balaraju, C. Anandan, and K. S. Rajam, "Influence of codeposition of copper on the structure and morphology of electroless Ni-W-P alloys from sulphate- and chloride-based baths," Surface and Coatings Technology, vol. 200, no. 12-13, pp. 3675-3681, 2006.

[24] F. Pearlstein, R. F. Weightman, and R. Wick, Metal Finishing, vol. 61, pp. 77-81, 1963.

[25] M. Palaniappa and S. K. Seshadri, "Friction and wear behavior of electroless Ni-P and Ni-W-P alloy coatings," Wear, vol. 265, no. 5-6, pp. 735-740, 2008.

[26] R. K. Roy, A Primer on the Taguchi Method, Society of Manufacturing Engineers, Dearborn, Mich, USA, 1990.

[27] P. Sahoo, "Wear behaviour of electroless Ni-P coatings and optimization of process parameters using Taguchi method," Materials and Design, vol. 30, no. 4, pp. 1341-1349, 2009.

[28] Minitab User Manual Release 13.2, Making Data Analysis Easier, MINITAB: State College, 2001. 

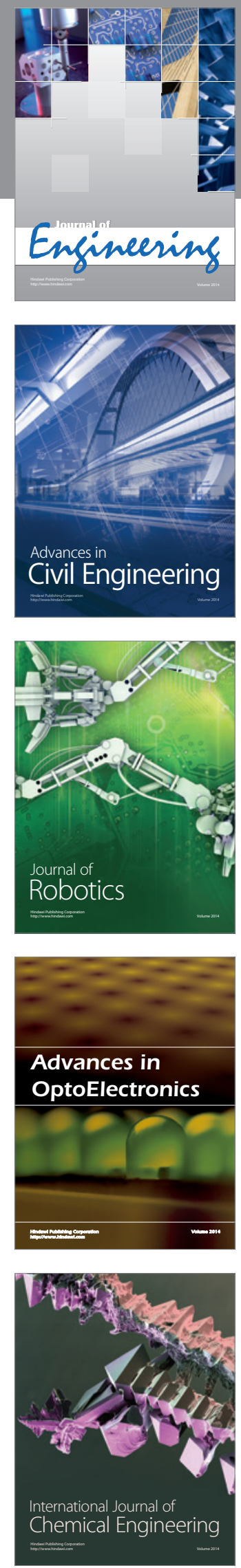

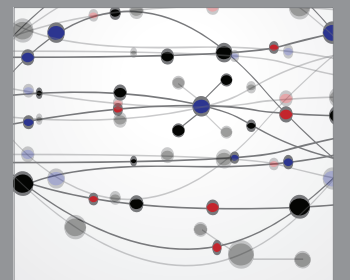

The Scientific World Journal
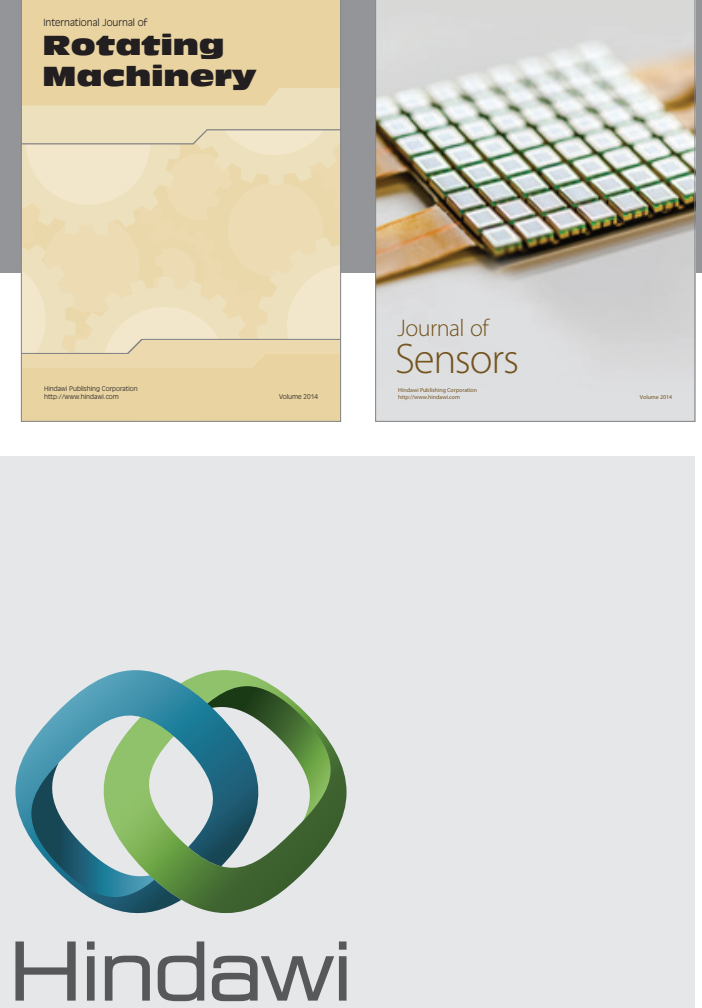

Submit your manuscripts at http://www.hindawi.com
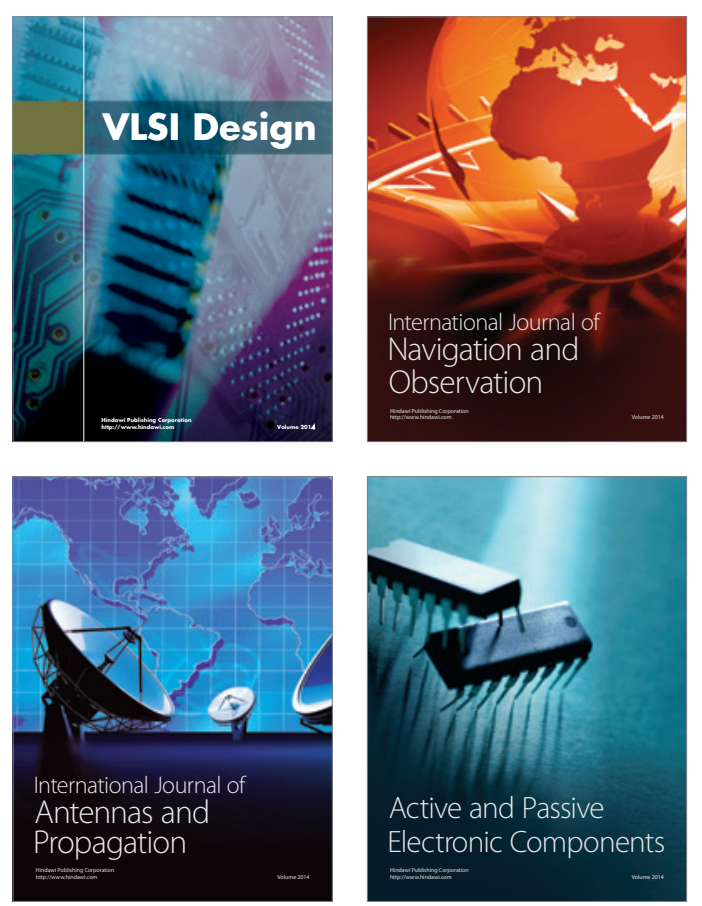
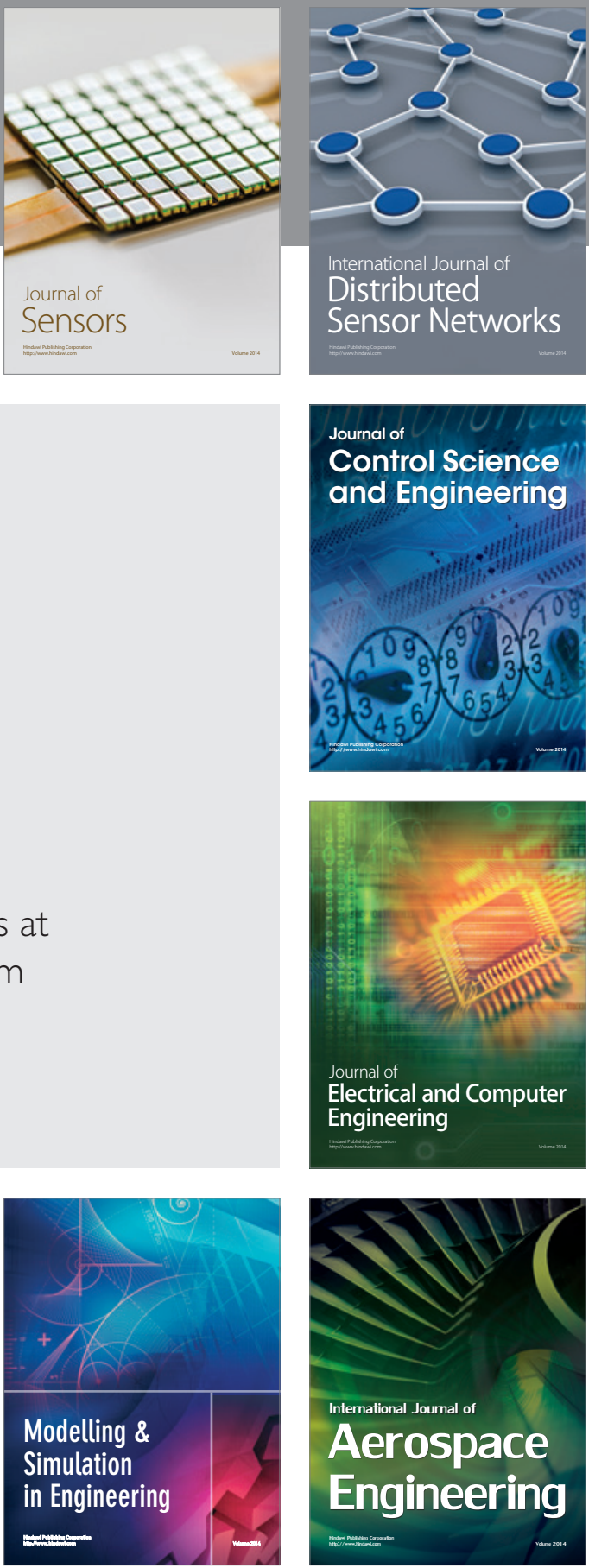

Journal of

Control Science

and Engineering
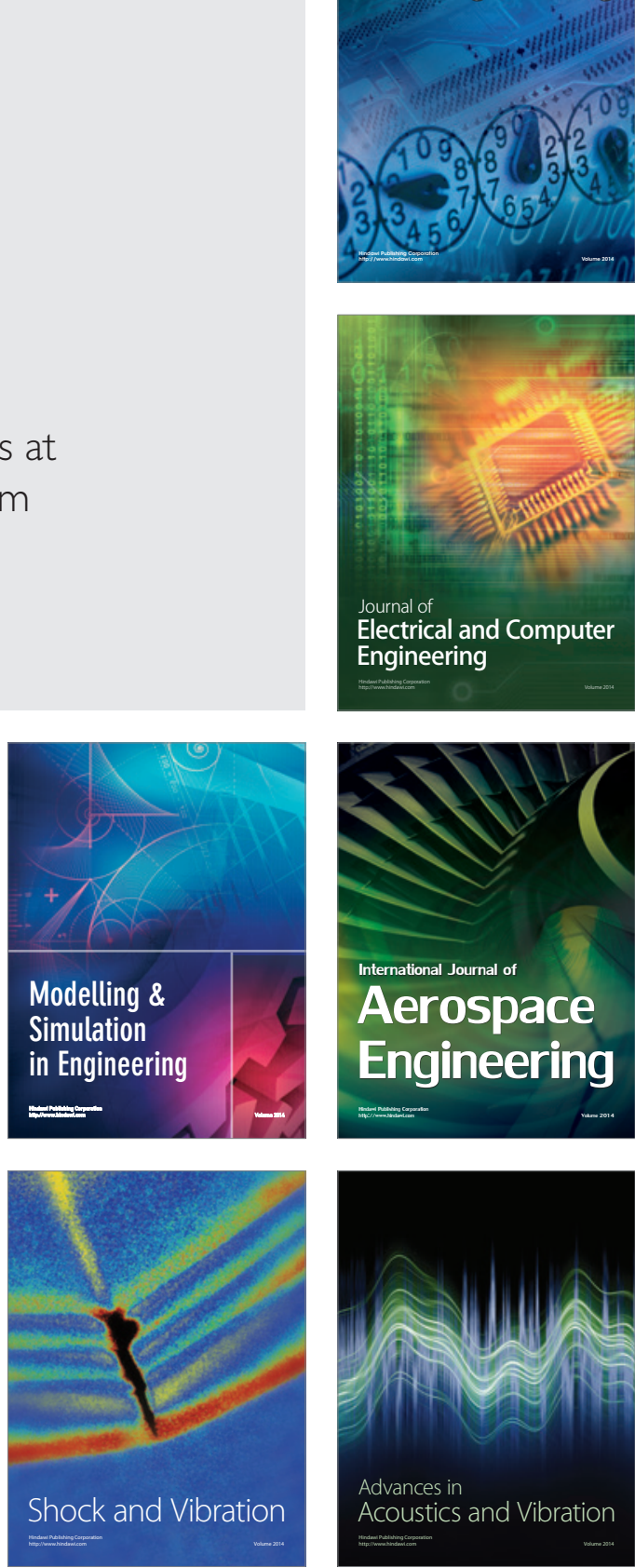